\title{
Influence of Sexual Function on the Social Relations and Quality of Life of Women with Premature Ovarian Insufficiency
}

\section{Influência da função sexual nas relações sociais e na qualidade de vida de mulheres com insuficiência ovariana prematura}

\author{
Daniela Angerame Yela ${ }^{1}$ Patricia Magda Soares ${ }^{1}$ Cristina Laguna Benetti-Pinto ${ }^{1}$ \\ ${ }^{1}$ Department of Obstetrics and Gynecology, Faculdade de Ciências \\ Médicas, Universidade Estadual de Campinas (Unicamp), Campinas, \\ São Paulo, Brazil \\ Address for correspondence Daniela Angerame Yela, PhD, \\ Universidade Estadual de Campinas, Rua Alexander Fleming 101, \\ Campinas, SP, 13083-970, Brazil (e-mail: yela@unicamp.br).
}

Rev Bras Ginecol Obstet 2018;40:66-71.

\begin{abstract}
Objective To evaluate the impact of sexual function (SF) in the quality of life (QoL) of women with premature ovarian insufficiency (POI).

Methods Case-control study in which 80 women with $\mathrm{POI}$ were evaluated using estrogen plus progestogen therapy, compared with 80 women matched by age ( \pm 2 years) and presenting preserved gonadal function. Sexual function was evaluated using the Female Sexual Function Index (FSFI), and the QoL was evaluated using the World Health Organization's (WHO) QoL assessment instrument (WHOQoL-BREF).

Results The mean age of the women with $\mathrm{POI}$ and of the control group was $38.4 \pm 7.3$ years and $38.1 \pm 7.3$ years respectively. The QoL, was worse among the $\mathrm{POI}$ group, and there were significant differences in the physical $(63.4 \pm 17.4$ and $72.7 \pm 15.2$ respectively, $p=0.0004)$ and psychological $(63.2 \pm 14.6$ and $69.3 \pm 13.9$ respectively, $p=0.0075$ ) domains among this group when compared with the control group. Women with $\mathrm{POI}$ presented significantly lower arousal, lubrication, orgasm and satisfaction, more dyspareunia and a worse FSFI scores when compared with the control group. All aspects of SF correlate directly with the worsening of the QoL regarding social relationships.

Conclusion Women with POI showed worse QoL and SF than the control group. The psychological aspects (desire, excitement, orgasm and sexual satisfaction) of SF had

\section{Keywords}

- premature ovarian insufficiency

- sexual disorders

- quality of life greater influence on the parameters of the QoL, while the physical aspects (pain and lubrication) had a low impact on the QoL. The poor SF in women with POI is directly correlated with a worsening across multiple domains of the QoL; however, the negative impact is particularly important in the social domain. These results suggest that the improvement in sexuality can improve the social interactions of women with POI.
\end{abstract}

received

August 3, 2017

accepted

November 14, 2017
DOI https://doi.org/

$10.1055 / \mathrm{s}-0037-1615289$.

ISSN 0100-7203.
Copyright $\odot 2018$ by Thieme Revinter

Publicações Ltda, Rio de Janeiro, Brazil
License terms

(요 (1) $\Theta \circledast$ 


\section{Resumo}

\section{Palavras-Chave}

- insuficiência ovariana prematura

- distúrbios sexuais

- qualidade de vida
Objetivo Avaliar o impacto da função sexual na qualidade de vida (QV) de mulheres com insuficiência ovariana prematura (IOP).

Métodos Estudo de caso-controle que avaliou 80 mulheres com IOP usando terapia hormonal combinada (progestagênio e estrogênio), em comparação com 80 mulheres com função gonadal preservada pareadas por idade ( \pm 2 anos). A função sexual (FS) foi avaliada por meio do índice de função sexual feminina (IFSF) e a QV, por meio do instrumento da Organização Mundial de Saúde (OMS) para avaliação da QV (WHOQoLBREF, na sigla em inglês).

Resultados A média etária das mulheres com IOP e do grupo controle foi de 38,4 \pm 7,3 e $38,1 \pm 7,3$ anos, respectivamente. A QV do grupo com IOP foi pior, e verificou-se uma diferença significativa nos domínios físico (63,4 $\pm 17,4$ e $72,7 \pm 15,2$, respectivamente, $p=0,0004)$ e psicológico $(63,2 \pm 14,6$ e $69,3 \pm 13,9$, respectivamente, $p=0,0075)$ para as mulheres com IOP quando comparadas com o grupo de controle. Mulheres com IOP apresentaram pior pontuação para excitação, lubrificação, orgasmo, satisfação, dispareunia, e pior índice de FS em comparação ao grupo controle. A piora em todos os aspectos da FS foi diretamente correlacionada com a piora no domínio das relações sociais da QV.

Conclusão Mulheres com IOP apresentaram pior QV e FS do que o grupo controle. Os aspectos psicológicos (desejo, excitação, orgasmo e satisfação sexual) da FS exerceram grande influência na $Q V$, enquanto os físicos (dor e lubrificação) exerceram pouca influência. A má função sexual em mulheres com IOP está diretamente correlacionada com uma piora em vários domínios da QV; porém, o impacto negativo é particularmente importante no domínio social, sugerindo que a melhora da sexualidade pode auxiliar na melhor integração social das mulheres com IOP.

\section{Introduction}

Premature ovarian insufficiency (POI) is a condition characterized by elevated gonadotrophins and sex steroid deficiency, which occurs in women under 40 years of age. ${ }^{1,2}$ It has physical and psychological consequences. ${ }^{3-8}$ Thus, young women with POI are more prone to present alterations in their sexuality ${ }^{9-11}$ and quality of life (QoL), ${ }^{12,13}$ causing tremendous damage to their relationships and self-esteem. The QoL of women with POI mainly affects their physical and psychological health; ${ }^{11,13}$ however, the influence of impaired sexual function (SF) on the QoL of women with POI is empirical and based on population studies of menopausal women at normal term age and/or presenting chronic diseases. ${ }^{5,14}$ There are several definitions of QoL; however, an analysis of these definitions suggests that QoL is a subjective construct, developed from objective aspects of existence and individual experience. Among the factors that influence QoL, sexuality should be regarded as a high-complexity factor. ${ }^{6,7}$ Considering that a poor SF (characterized by a sexual dysfunction) may negatively influence the QoL, and that the lack of knowledge limits the possibility of structuring specialized medical and psychological care for POI patients, this study aims to provide information about the aspects of sexuality that can influence different domains of QoL and how they are interrelated.

\section{Methods}

A case-control study matched by age was performed in the Gynecological Endocrinology Outpatient Clinic of the Department of Obstetrics and Gynecology of our institution.

This study evaluated 80 women diagnosed with POI (hypergonadotropic hypoestrogenic amenorrhea before 40 years of age, with follicle-stimulating hormone [FSH] levels $\geq 40 \mathrm{mIU} / \mathrm{mL}$ at 2 different periods of time $)^{1}$ who were receiving care at the Gynecological Endocrinology Outpatient Clinic of our institution for a period of 24 months. All of the women included were treated with estrogen plus progestogen therapy (estradiol plus norethisterone, conjugated estrogens plus medroxyprogesterone, ethinyl estradiol plus levonorgestrel, according to a precise indication). Each one was compared with a woman of the same age ( \pm 2 years, control group), who was followed at the Family Planning Outpatient Clinic of the same center, and who presented preserved gonadal function (spontaneous menstrual cycles with intervals of 24 to 35 days), ${ }^{15}$ with no use of hormonal drugs or hormonal contraceptives. Each woman should have had at least one heterosexual intercourse in the previous month.

Women who presented chronic diseases that could affect QoL or sexuality, or who used drugs that could interfere with sexuality (such as antidepressants), and those who presented cognitive deficit were excluded to reduce potential sources of bias from both groups. The women in both groups were 
interviewed individually by the researcher, who used questionnaires to assess SF (the Female Sexual Function Index, FSFI) and QoL (the World Health Organization's [WHO] QoL assessment instrument, WHOQOL-BREF) in a reserved room while they waited for their routine consultations in the outpatient clinic.

The project was approved by the Ethics in Research Committee (no. 672/2008), and all study subjects signed a consent form before being enrolled.

\section{Sexual Function Assessment}

The FSFI questionnaire, ${ }^{16}$ which was validated for the Portuguese language and the Brazilian female population, ${ }^{17}$ was used to evaluate sexual function. This tool has nineteen questions grouped into six domains that measure desire, arousal, lubrication, orgasm, satisfaction and pain or discomfort during sexual intercourse. Each aspect is scored on a scale from 0 to 6 , with higher scores indicating better functioning in each domain. The total FSFI score is calculated adding the scores for each domain. The score for sexual dysfunction for this index is $\leq 26.5$. $^{16}$

\section{Quality of Life Assessment}

The instrument used to assess the QoL was the WHOQoLBREF, which was developed by The WHOQoL Group (1998) ${ }^{18}$ and validated in Brazil by Fleck et al in $2000 .^{19}$ The questionnaire has 26 questions, 2 of which are general, in which the woman describes her impression of her QoL and health, and the other 24 questions cover four domains: physical, psychological, social relationships and environment. The evaluation is performed by assigning for each question scores that are added and evaluated according to a scale from 0 to 100 , in which 0 is the worst possible quality of life, and 100 is the best possible quality of life. ${ }^{18}$

\section{Statistical Analysis}

A convenience sample of women receiving care at our institution for 24 months was analyzed. The variables were tested for normality distribution using the Kolmogorov-Smirnov test. The results of the different domains of the QoL and sexuality questionnaires were compared between the POI and control groups using the Student $t$-test, and when the data did not show any parametric distribution, the Mann-Whitney test was used. The Spearman correlation was used to evaluate the correlation coefficient of each SF domain on different aspects of QoL. Considering the convenience sample, the test power was calculated. Data were considered significant when $p<0.05$. All statistical analyzes were performed using the Statistical Analysis System (SAS, SAS Institute, Cary, NC, US) software, version 9.2 for Windows.

\section{Results}

The mean age \pm standard deviation (SD) of the women in the POI group $(n=80)$ and in the control group $(n=80)$ was $38.4 \pm 7.3$ and $38.1 \pm 7.3$ years respectively $(p=0.72)$. In the POI group, the women were $30.2 \pm 7.0$ years old when they had their last menstrual period. The time since the onset of gonadal insufficiency was of $8.2 \pm 5.8$ years.
In the evaluation of the WHOQoL-BREF, there was a worsening in the assessment of the physical (63.4 \pm 17.4 and $72.7 \pm 15.2$ respectively, $p=0.0004)$ and psychological $(63.2 \pm 14.6$ and $69.3 \pm 13.9$ respectively, $p=0.0075)$ domains in the POI group when compared with the control group, although no differences were found between the groups in the self-perception of their QoL and health (-Table 1).

The POI group scored worse than the control group in the FSFI (24.0 \pm 5.7 and $27.7 \pm 4.6$ respectively, $p<0.0001)$. For the domains of arousal, lubrication, orgasm and satisfaction, the POI group scores were also worse, and these women reported more pain during the sexual act than the controls ( $\mathbf{- T a b l e ~} \mathbf{1}$ ).

By comparing the results of the POI group in the FSFI and WHOQoL-BREF questionnaires, we noted that orgasm and, in particular, sexual satisfaction were SF domains that were correlated with all QoL domains in women with POI. The physical domains of the SF, such as pain and lubrication, were less frequently correlated with QoL. Moreover, we noted that the total FSFI score, which assesses sexual function in general, was positively correlated to the self-perception of QoL in women with POI ( $\mathrm{R}=0.26, p=0.021$ ) (-Table 2).

On the other hand, social relationships was the domain that suffered the most influence of all aspects of sexual function in the POI group. Arousal, orgasm, satisfaction and pain were the items that presented the highest coefficient of determination with the women's social relationships, so the more affected they were, the worse their social interactions $(R=0.48$, $p<0.0001 ; \mathrm{R}=0.41, \quad p<0.0001 ; \mathrm{R}=0.63, \quad p<0.0001$; and $\mathrm{R}=0.45, p<0.0001$ respectively) ( - Table 2 ).

\section{Discussion}

The present study, which evaluated the association between SF and QoL among women with POI but without chronic diseases, showed that the worsening of any domain of sexuality can negatively impact the way these women interact socially. The psychological domains of SF (arousal, orgasm, and especially sexual satisfaction) had greater influence than the physical domains (pain and lubrication) on the QoL parameters.

Quality of life reviews have been the subject of interest in different areas, and often serve as guidelines for health managers. Biopsychosocial domains are interrelated in this context. ${ }^{20}$ Our results call attention to the fact that the known sexuality impairment in women with POI worsens their QoL, notwithstanding the presence of other chronic diseases. This impact had not been studied previously in women with POI but without chronic diseases, and the present study highlights the complex interaction between these contexts.

In terms of other chronic diseases, this interaction has been described in young women with POI due to a hematological cancer treatment, for example, for whom a worse QoL lead to a worsening of their sexual life. ${ }^{21}$ Absolom et al, ${ }^{21}$ studying women with POI due to cancer treatment, showed that the physical and mental health of these women was significantly impaired compared with young women without the same diagnosis. These authors pointed out that the negative symptoms of hypoestrogenism, such as hot flashes, night sweats and vaginal dryness, lead to a worsening in QoL and sexual activity. ${ }^{22}$ 
Table 1 Comparison of the different domains of quality of life and sexual function in women with premature ovarian insufficiency (POI group) and women with normal gonadal function (control group)

\begin{tabular}{|c|c|c|c|c|c|c|c|}
\hline & POI grou & 80) & & Control $\subseteq$ & $n=80$ & & \\
\hline Measurement & Average & SD & Mean & Average & SD & Mean & $p$ \\
\hline Age & 38.4 & 7.3 & 39.0 & 38.1 & 7.3 & 38.0 & 0.7279 \\
\hline Quality of life & & & & & & & \\
\hline Physical & 63.4 & 17.4 & 62.5 & 72.7 & 15.2 & 75.0 & 0.0004 \\
\hline Psychological* & 63.2 & 14.6 & 62.5 & 69.3 & 13.9 & 70.8 & 0.0075 \\
\hline Social & 67.2 & 20.3 & 70.8 & 69.7 & 17.5 & 75.0 & 0.5713 \\
\hline Environment* & 59.1 & 13.8 & 59.4 & 61.5 & 12.6 & 59.4 & 0.2466 \\
\hline QoL domain & 72.5 & 17.2 & 75.0 & 75.0 & 13.8 & 75.0 & 0.3782 \\
\hline Health & 59.7 & 25.9 & 75.0 & 65.9 & 19.6 & 75.0 & 0.2505 \\
\hline Sexual functio & & & & & & & \\
\hline Desire & 3.4 & 1.2 & 3.6 & 3.7 & 1.0 & 3.6 & 0.1411 \\
\hline Arousal & 3.8 & 1.1 & 3.6 & 4.4 & 0.9 & 4.5 & 0.0006 \\
\hline Lubrication & 4.1 & 1.3 & 4.1 & 5.0 & 1.1 & 5.4 & $<0.0001$ \\
\hline Orgasm & 3.9 & 1.4 & 4.0 & 4.6 & 1.2 & 5.2 & 0.0006 \\
\hline Satisfaction & 4.5 & 1.2 & 4.8 & 5.0 & 1.1 & 5.2 & 0.0061 \\
\hline Pain & 4.3 & 1.3 & 4.4 & 5.1 & 1.0 & 5.2 & 0.0004 \\
\hline Total score & 24.0 & 5.7 & 23.6 & 27.7 & 4.6 & 28.9 & $<0.0001$ \\
\hline
\end{tabular}

Abbreviation: POI, premature ovarian insufficiency; SD, standard deviation/Mann-Whitney test.

Note: * Student $t$-test.

Table 2 Correlation between quality of life and sexual function in women with premature ovarian insufficiency $(n=80)$

\begin{tabular}{|c|c|c|c|c|c|c|c|c|c|c|c|c|c|c|}
\hline \multirow{2}{*}{ QoL } & \multicolumn{2}{|c|}{ Desire } & \multicolumn{2}{|c|}{ Arousal } & \multicolumn{2}{|c|}{ Lubrification } & \multicolumn{2}{|c|}{ Orgasm } & \multicolumn{2}{|c|}{$\begin{array}{l}\text { Sexual } \\
\text { satisfaction }\end{array}$} & \multicolumn{2}{|l|}{ Pain } & \multicolumn{2}{|c|}{ Total FSFI } \\
\hline & $\mathbf{R}$ & $p$ & $\mathrm{R}$ & $p$ & $\mathbf{R}$ & $p$ & $R$ & $p$ & $R$ & $p$ & $R$ & $p$ & $\mathbf{R}$ & $p$ \\
\hline Physical & 0.09 & 0.427 & 0.21 & 0.066 & 0.13 & 0.247 & 0.26 & 0.022 & 0.30 & 0.006 & 0.15 & 0.191 & 0.26 & 0.022 \\
\hline Psychological & 0.08 & 0.472 & 0.25 & 0.026 & 0.17 & 0.141 & 0.29 & 0.008 & 0.30 & 0.006 & 0.13 & 0.235 & 0.27 & 0.015 \\
\hline Social & 0.35 & 0.002 & 0.48 & $<0.0001$ & 0.31 & 0.005 & 0.41 & 0.0001 & 0.63 & $<0.0001$ & 0.45 & $<0.0001$ & 0.37 & $<0.0001$ \\
\hline Environment & 0.21 & 0.055 & 0.31 & 0.004 & 0.27 & 0.017 & 0.33 & 0.002 & 0.45 & $<0.0001$ & 0.09 & 0.402 & 0.37 & 0.0008 \\
\hline QoL domain & 0.04 & 0.740 & 0.21 & 0.055 & 0.19 & 0.095 & 0.36 & 0.001 & 0.34 & 0.002 & 0.03 & 0.801 & 0.26 & 0.021 \\
\hline Health & 0.02 & 0.828 & 0.21 & 0.061 & 0.05 & 0.644 & 0.34 & 0.002 & 0.26 & 0.019 & 0.07 & 0.552 & 0.21 & 0.053 \\
\hline
\end{tabular}

Abbreviations: FSFI, Female Sexual Function Index; QoL, quality of life; R, Spearman correlation coefficient; SF, sexual function.

We evaluated women with POI undergoing estro-progestative hormone therapy and without chronic diseases, and we still found the same impairment and interaction. These data seem to indicate that the loss of gonadal function has a direct influence on SF and QoL, despite the treatment of the hypoestrogenism and the other chronic diseases.

In the present study, we observed that the overall assessment of SF (total FSFI score) had a weak but significant correlation with the physical and psychological domains of QoL in the POI group. Other authors who evaluated women with chronic illnesses (without gonadal failure) also showed that the physical domain of QoL and overall SF were positively correlated. ${ }^{23,24}$

The questionnaires that assess overall SF are made up of physical domains (pain and lubrication) and psychological domains (desire, arousal, orgasm and satisfaction). In a separate analysis of the physical aspects of sexuality, these domains were observed to have a low impact on quality of life. The psychological domains of SF (in particular satisfaction), on the other hand, influence almost all of the QoL domains. Sexual satisfaction was the aspect with the greatest positive impact on the context of social interaction, and it was measured by questions that assess the relationship with friends, relatives, and the degree of satisfaction of the women with themselves. In addition to these particular features, one can observe that the better the overall sexual performance (total FSFI score), the better the evaluation of the social interactions of these women.

According to the literature, women with POI have a worse assessment of their self-image, worse self-confidence, report 
feeling less feminine and older, and feeling different from other women of the same age. ${ }^{25}$ These issues appear to be linked to a psychological context: the diagnosis of POI affects the sexuality and the interactions of these women with their peers. Our results are in agreement with those of the literature: there is a direct correlation between the psychological and social evaluations of women with POI and the FSFI.

To the best of our knowledge, this is the first study to evaluate the influence of sexuality on the QoL of women with POI but without other diseases.

It is necessary to highlight the influence of changes of sexuality on the social context, since sexuality is a result of interactive behaviors and attitudes between individuals; of strategies to attract and keep a partner, forming a couple, ultimately, for the reproduction and survival of the species. As sexuality is expressed through means learned through socialization and its purpose is related to the survival of the species, a strong interaction between sexuality and society is expected. Thus, the social context is essential when considering potentially sexual behavior.

Sexuality involves affectivity, the ability to compromise, the ability to form and maintain relationships, and procreation. The definitive and early loss of the ability to procreate very likely alters the expression of sexuality, with a negative impact on interpersonal relationships and social interactions in general.

We believe that the results of the present study should alert healthcare professionals regarding specific practices needed for women with POI, making them adapt better this condition, in order to improve their social relationships and make them understand their role in society.

\section{Conclusion}

In conclusion, the psychological aspects (desire, excitement, orgasm and sexual satisfaction) of the SF had a great influence on the parameters of the QoL, while the physical aspects (pain and lubrication) had a low impact on the QoL. Sexual function and QoL in women with POI are directly related, especially regarding the social domain. Aworse sexual function is related to the deterioration of social interactions. These results should be considered during the medical and psychological cares offered.

\section{Contributions}

Yela DA, Soares PM and Benetti-Pinto CL contributed with the project and interpretation of data, writing of the article, critical review of the intellectual content, and final approval of the version to be published.

\section{Conflicts of Interest}

The authors have no conflicts of interest to declare.

\section{References}

1 Nelson LM. Clinical practice. Primary ovarian insufficiency. N Engl J Med 2009;360(06):606-614. Doi: 10.1056/NEJMcp0808697

2 Rafique S, Sterling EW, Nelson LM. A new approach to primary ovarian insufficiency. Obstet Gynecol Clin North Am 2012;39(04): 567-586. Doi: 10.1016/j.ogc.2012.09.007
3 Baba Y, Ishikawa S, Amagi Y, Kayaba K, Gotoh T, Kajii E. Premature menopause is associated with increased risk of cerebral infarction in Japanese women. Menopause 2010;17(03):506-510. Doi: 10.1097/gme.0b013e3181c7dd41

4 Singer D, Mann E, Hunter MS, Pitkin J, Panay N. The silent grief: psychosocial aspects of premature ovarian failure. Climacteric 2011;14(04):428-437. Doi: 10.3109/13697137.2011.571320

5 Popat VB, Calis KA, Vanderhoof VH, et al. Bone mineral density in estrogen-deficient young women. J Clin Endocrinol Metab 2009; 94(07):2277-2283. Doi: $10.1210 /$ jc.2008-1878

6 Schairer LC, Foley FW, Zemon V, et al. The impact of sexual dysfunction on health-related quality of life in people with multiple sclerosis. Mult Scler 2014;20(05):610-616. Doi: 10.1177/13524585 13503598

7 Bauld R, Brown RF. Stress, psychological distress, psychosocial factors, menopause symptoms and physical health in women. Maturitas 2009;62(02):160-165. Doi: 10.1016/j.maturitas.2008. 12.004

8 Schover LR. Premature ovarian failure and its consequences: vasomotor symptoms, sexuality, and fertility. J Clin Oncol 2008; 26(05):753-758. Doi: 10.1200/JCO.2007.14.1655

9 de Almeida DM, Benetti-Pinto CL, Makuch MY. Sexual function of women with premature ovarian failure. Menopause 2011;18(03): 262-266. Doi: 10.1097/gme.0b013e3181f4318d

10 van der Stege JG, Groen H, van Zadelhoff SJ, et al. Decreased androgen concentrations and diminished general and sexual well-being in women with premature ovarian failure. Menopause 2008;15(01):23-31. Doi: 10.1097/gme.0b013e3180f6108c

11 Kalantaridou SN, Vanderhoof VH, Calis KA, Corrigan EC, Troendle $\mathrm{JF}$, Nelson LM. Sexual function in young women with spontaneous 46,XX primary ovarian insufficiency. Fertil Steril 2008;90(05): 1805-1811. Doi: 10.1016/j.fertnstert.2007.08.040

12 Benetti-Pinto CL, de Almeida DM, Makuch MY. Quality of life in women with premature ovarian failure. Gynecol Endocrinol 2011;27(09):645-649. Doi: 10.3109/09513590.2010.520374

13 Nappi RE, Lachowsky M. Menopause and sexuality: prevalence of symptoms and impact on quality of life. Maturitas 2009;63(02): 138-141. Doi: 10.1016/j.maturitas.2009.03.021

14 Ambler DR, Bieber EJ, Diamond MP. Sexual function in elderly women: a review of current literature. Rev Obstet Gynecol 2012;5 (01):16-27. Doi: 10.3909/riog0156

15 Munro MG, Critchley HO, Fraser IS. The FIGO classification of causes of abnormal uterine bleeding: Malcolm G. Munro, Hilary O.D. Crithcley, Ian S. Fraser, for the FIGO Working Group on Menstrual Disorders. Int J Gynaecol Obstet 2011;113(01):1-2. Doi: 10.1016/j. ijgo.2011.01.001

16 Rosen R, Brown C, Heiman J, et al. The Female Sexual Function Index (FSFI): a multidimensional self-report instrument for the assessment of female sexual function. J Sex Marital Ther 2000;26 (02):191-208. Doi: 10.1080/009262300278597

17 Thiel RdoR, Dambros M, Palma PCR, Thiel M, Riccetto CLZ, Ramos MdeF. [Translation into Portuguese, cross-national adaptation and validation of the Female Sexual Function Index]. Rev Bras Ginecol Obstet 2008;30(10):504-510. Doi: 10.1590/S01007203200800100000

18 The WHOQOL Group. Development of the World Health Organization WHOQOL-BREF quality of life assessment. Psychol Med 1998;28(03):551-558. Doi: 10.1017/S0033291798006667

19 Fleck MPA, Louzada S, Xavier M, et al. Application of the Portuguese version of the abbreviated instrument of quality life WHOQOL-bref. Rev Saude Publica 2000;34(02):178-183. Doi: 10.1590/S003489102000000200012

20 Maclaran K, Panay N. Current concepts in premature ovarian insufficiency. Womens Health (Lond) 2015;11(02):169-182. Doi: $10.2217 /$ whe. 14.82

21 Absolom K, Eiser C, Turner L, et al; Late Effects Group Sheffield. Ovarian failure following cancer treatment: current management 
and quality of life. Hum Reprod 2008;23(11):2506-2512. Doi: 10.1093/humrep/den285

22 Coelho-Marques FZ, Wagner MB, Poli de Figueiredo CE, d'Avila DO. Quality of life and sexuality in chronic dialysis female patients. Int J Impot Res 2006;18(06):539-543. Doi: 10.1038/sj.ijir.3901470

23 Seethala S, Hess R, Bossola M, Unruh ML, Weisbord SD. Sexual function in women receiving maintenance dialysis. Hemodial Int 2010;14(01):55-60. Doi: 10.1111/j.1542-4758.2009.00404.x
24 Basok EK, Atsu N, Rifaioglu MM, Kantarci G, Yildirim A, Tokuc R. Assessment of female sexual function and quality of life in predialysis, peritoneal dialysis, hemodialysis, and renal transplant patients. Int Urol Nephrol 2009;41(03):473-481. Doi: 10.1007/s11255-008-9475-z

25 Graziottin A. Menopause and sexuality: key issues in premature menopause and beyond. Ann N Y Acad Sci 2010;1205:254-261. Doi: $10.1111 /$ j.1749-6632.2010.05680.x 